\title{
An Identified Motoneuron with Variable Fates in Embryonic Zebrafish
}

\author{
Judith S. Eisen, Susan H. Pike, and Babette Romancier \\ Institute of Neuroscience, University of Oregon, Eugene, Oregon 97403
}

\begin{abstract}
Every trunk hemisegment of the zebrafish is innervated by 3 identified primary motoneurons whose development can be observed directly in living embryos. In this paper, we describe another identified neuron that is part of this system. Unlike the other primary motoneurons which are present in all trunk hemisegments, this cell is present in slightly less than half of the trunk hemisegments. Additionally, this cell has at least 2 different fates: it may become a primary motoneuron and arborize in an exclusive muscle territory, or it may die during embryonic development. We have named this cell VaP, for variable primary. We show that the presence of VaP does not affect the early development of the other primary motoneurons in the same hemisegment. Moreover, we show that ablation of both $\mathrm{VaP}$ and caudal primary does not alter pathfinding by another identified primary motoneuron.
\end{abstract}

During development, the growth cones of individual neurons must find and recognize their appropriate targets from among a large number of cells that are functionally inappropriate synaptic partners. The question of how this is accomplished is a central issue in developmental neuroscience. Detailed study of this process is facilitated by "simple" systems in which neurons can be uniquely identified, and the same neuron can be studied in each individual of the species. Such systems are common among invertebrates; studies from insects, crustaceans, worms, and molluscs have been fundamental to our current understanding of neuronal development. Although less common among vertcbrates, recent work demonstrates that some fish embryos also have individually identifiable neurons (Eisen et al., 1986; Kuwada, 1986; Metcalfe et al., 1986; Myers et al., 1986) and that the development of these cells can be observed directly in living embryos (Eisen et al., 1986; Myers et al., 1986).

The system of motoneurons innervating the axial musculature of the zebrafish is just such a simple system that has been exploited in studying the ability of developing neurons to select pathways that lead toward their cell-specific targets. The trunk musculature of the adult zebrafish is segmentally arranged (Westerfield et al., 1986), and each side of every trunk muscle segment is innervated by 3 identified motoneurons (Westerfield et al., 1986) called primary motoneurons (Myers, 1985) by analogy

\footnotetext{
Received Mar. 8, 1989; revised June 13, 1989; acceptcd Junc 26, 1989.

We thank Harry Howard, Sumita Ray, Scan Poston, and Ed Sullivan for technical assistance, Steve Johnson and Peter O'Day for advice on statistical methods Monte Westerfield, Charles Kimmel, Peter O'Day, Eric Hanneman, Bettina Debu, Paul Myers, and Christine Gatchalian for comments on the manuscript, and Bil Trevarrow for the zn-1 monoclonal antibody. Supported by NS239 I 5, BNS8553 146 , the Procter and Gamble Company, the Murdock Charitable Trust, a Searle Scholar Award to J.S.E, and a Patricia Roberts Harris Fellowship to S.H.P.

Correspondence should be addressed to Judith $\mathrm{S}$. Eisen at the above address.

Copyright (c) 1990 Society for Neuroscience $0270-6474 / 90 / 010034-10 \$ 02.00 / 0$
}

with the primary motoneurons of amphibia (Blight, 1978). These cells have been named for their relative rostrocaudal positions in the spinal cord (Eisen et al., 1986); in each hemisegment CaP is the most caudal primary motoneuron, RoP is the most rostral primary motoneuron, and $\mathrm{MiP}$ is the middle primary motoneuron. Previous work demonstrated that during embryonic development each of the primary motoneurons grows an axon that projects accurately to the region of muscle appropriate for its adult function (Eisen et al., 1986; Myers et al., 1986). The primary motoneurons in each hemisegment elaborate axons in a stereotyped order in which CaP precedes MiP and MiP precedes RoP. In addition to the primary motoneurons, each hemisegment is innervated by a number of secondary motoneurons (Myers, 1985; Westerfield et al., 1986); some of these cells may also be individually identifiable, although less is known about them at this time.

While examining interactions between primary motoneurons that might contribute to accurate pathway selection (Eisen et al., 1989), we made some surprising observations about the organization of this system. Although the 3 identified primary motoneurons are present in each hemisegment and follow the same stereotyped pattern of axonal outgrowth, in about half of the embryonic hemisegments there is a fourth primary motoneuron. We have named this cell $\mathrm{VaP}$, for variable primary, because of variability it shows in a number of different features. In this paper we describe the development of $\mathrm{VaP}$ and show that it can be distinguished from the other primary motoneurons by the following criteria: (1) it is present in only about half of the trunk hemisegments; (2) it arborizes in a unique muscle territory not innervated by other primary motoneurons; and (3) many, perhaps most, VaPs die during embryonic development. The presence of VaP does not appear to alter cell-specific pathway selection by the other primary motoneurons. Moreover, we have extended previous studies (Eisen et al., 1989) and show that ablation of $\mathrm{CaP}$ and $\mathrm{VaP}$ does not appear to affect pathfinding by later-growing primary motoneurons.

One of the interesting ways in which VaP differs from the other primary motoneurons is that many VaPs die during embryonic development. In invertebrates cell number is often invariant, and death of particular neurons functions to regulate the size of a neuronal population or to delete a cell whose function is unnecessary (Truman, 1984). In vertebrates, more neurons of many types, including motoneurons, are produced during embryogenesis than are found at later developmental stages (Purves and Lichtman, 1985). Death of the "extra" cells is thought to be important in regulating the final number of neurons that innervate a specific target. The discovery of an identified vertebrate neuron that dies during embryogenesis may afford us the opportunity to explore the mechanisms regulating neuronal survival in vertebrates at the level of individual cells. 


\section{Materials and Methods}

Animals. Zebrafish embryos were obtained from our laboratory colony and were maintained as described previously (Myers et al., 1986). Embryos were staged by hours postfertilization at $28.5^{\circ} \mathrm{C}(\mathrm{h})$. In this paper we refer to trunk segments and to trunk hemisegments. The first trunk segment is the region defined by the first bilateral pair of myotomes (myol; see Hanneman et al., 1988) and includes the first spinal segment (sp1). A hemisegment is one side (right or left) of a trunk segment and includes both the myotome and the appropriate half of the spinal cord.

Intracellular dye labeling. Embryos of $16-30 \mathrm{~h}$ were positioned on microslides, and individual motoneurons were impaled with dye-filled microelectrodes as described in Eisen et al. (1989). For embryos older than $18 \mathrm{~h}, 1-2 \mathrm{~mm}$ tricaine-methane sulfonate was added to the saline to prevent spontaneous muscle contractions (Myers et al., 1986). For studies in which 2 motoneurons in a hemisegment were labeled, the first motoneuron was injected iontophoretically with sulforhodamine 101 (gift of Molecular Probes) and the second motoneuron injected iontophoretically with Lucifer yellow (Molecular Probes); cells were then photographed using Fujichrome P1600 film.

Chronic labeling. Individual motoneurons were labeled either by injection of precursor blastomeres with rhodamine dextran as described in Eisen et al. (1986) (hereafter referred to as the "lineage tracer" method) or by direct application of the fluorescent lipid-soluble dye (Honig and Hume, 1986) 1,1'-dioctadecyl-3,3,3',3'-tetramethylindocarbocyanine perchlorate (Di-I; Molecular Probes) to the cell body. Di-I (0.5\%) was dissolved in $n, n$-dimethylformamide (Sigma), filtered, placed in 0.5 $\mathrm{ml}$ aliquots, and stored frozen at $-20^{\circ} \mathrm{C}$. The tips of blunt microelectrodes were filled with the dye solution, the electrodes advanced to within $1-5 \mu \mathrm{m}$ of a motoneuron, and dye ejected with a brief $(10-100$ msec) pressure pulse from a picospritzer (General Valve Corp.) or a picopump (WPI). Labeled motoneurons were viewed using a Dark Invader image intensifier (Meyers) and CCD array camera (Pulnix) to prevent illumination-induced damage (see Eisen et al., 1986). The signal from the camera was displayed on a high-resolution video monitor (Lenco) and recorded on a time-lapse video recorder (Gyyr).

Single-cell ablations. Individual motoneurons were ablated by laserirradiation as described in Eisen et al. (1989).

Retrograde labeling of motoneuronal somata. Primary motor somata were labeled by retrograde transport of Di-I applied to the ventral root or the peripheral nerve with pressure pulses.

Antibody labeling. Primary motoneurons were labeled with the $\mathrm{zn}-1$ monoclonal antibody as described in Myers et al. (1986) and Eisen et al. (1989).

Nomarski observations of the presence or absence of VaP. Embryos of 18-23 h were anesthetized in 1-2 mM tricaine-methane sulfonate, embedded in $1.2 \%$ agar in a dilute saline (Kimmel and Warga, 1987), and positioned on microslides so that both sides of trunk segments 511 could be viewed with Nomarski optics using a $50 \times$ water-immersion objective (Leitz fluoreszenz) mounted on a compound microscope (Zeiss). The right side of the embryo always faced the objective. The right and left side of each segment was scored for the presence of a single primary motoneuron in the $\mathrm{CaP} / \mathrm{VaP}$ position or 2 motoneurons in the $\mathrm{CaP} /$ $\mathrm{VaP}$ position. Embryos were discarded if both sides of segments 5-11 could not be seen clearly. Of the 47 embryos scored, 1 was examined independently by 2 of the investigators (J.S.E. and S.H.P.), and the results obtained for all 14 hemisegments were the same.

\section{Results}

Early development of $\mathrm{VaP}$

Early in development, the somata of 1 or 2 primary motoneurons could be seen in trunk spinal hemisegments using Nomarski optics. The earliest developmental time that the somata of primary motoneurons could be recognized was at about $15 \mathrm{~h}$, when the 14th somite was just beginning to pinch off from the unsegmented mesoderm. Typically, the soma of a single primary motoneuron was seen at this time in trunk spinal hemisegments. This cell was easily recognized by its characteristic location on the ventrolateral edge of the spinal cord half-way between the myosepta delineating adjacent somites and by its large size (Fig. $1 A$ ). In a few hemisegments, the soma of a second primary motoncuron was apparent adjacent to the first primary moto- neuron at this stage (Fig. $1 B$ ). In some other hemisegments, the soma of a second primary motoneuron appeared slightly later, within 0.5-1.0 hr. In yet other hemisegments, a second soma did not appear adjacent to the first primary motoneuron. As we describe below, in cases in which a single soma was present, this cell was $\mathrm{CaP}$. In cases in which 2 somata were present, one of these cells was CaP and the other was VaP. In hemisegments lacking VaP, CaP extended a growth cone at about 16.5-17.5 $h$ (Fig. 1C). In hemisegments containing both $\mathrm{CaP}$ and VaP, these 2 cells extended growth cones at the same stage and within a few minutes of one another (Fig. $1 D$ ).

Our Nomarski observations raised several questions about $\mathrm{VaP}, \mathrm{CaP}$, and the relationship between these cells. First, was VaP really absent from those segments in which we did not recognize it using Nomarski optics? Second, were $\mathrm{CaP}$ and VaP distinctly different cells, and, if so, how could we distinguish them? Finally, were $\mathrm{CaP}$ and $\mathrm{VaP}$ lineally related, as suggested by their close resemblance (see Fig. $1 D$ )?

$V a P$ is not present in every hemisegment. Because each of the other 3 primary motoneurons is present in every hemisegment (Myers, 1985; Eisen et al., 1986; Myers et al., 1986; Westerfield et al., 1986), we wondered whether VaP might be cryptic in the hemisegments in which it appeared to be absent by Nomarski observations. For example, if the VaP soma was medial to the CaP soma, we might not be able to see it using Nomarski optics. To address this question, we used an independent method to ensure that our Nomarski observations accurately reflected the presence or absence of VaP. First, we examined individual hemisegments in 19-20 h embryos and scored them for the presence or absence of VaP using Nomarski optics. Then we labeled the motoneuronal somata in the same hemisegments by ejecting Di-I in the region of the developing motor nerve. The Di-I was transported retrogradely by the motor axons, and the somata of the primary motoneurons became labeled. In all 27 cases in which only a single soma was observed in the spinal cord at the CaP/VaP position using Nomarski optics, retrograde labeling revealed a single soma (Fig. 2, $A, B$ ). Retrograde labeling revealed 2 somata in 35 of 37 cases in which 2 somata were obscrved at the CaP/VaP position using Nomarski optics (Fig. $2, C, D$ ). In the other 2 cases in which the soma seen with Nomarski optics was not labeled by retrograde transport of DiI, we labeled it by direct application of Di-I. In both cases, the cell was an interneuron. Thus, we conclude that our observations are accurate in showing that when $\mathrm{VaP}$ is not visible with Nomarski optics, it is not present. However, we may have slightly overestimated the occurrence of $\mathrm{VaP}$, because some hemisegments may contain interneurons with similar-appearing somata. This possibility will be further discussed below.

$\mathrm{VaP}$ and $\mathrm{CaP}$ are distinct cells. Because of the close resemblance between $\mathrm{CaP}$ and VaP during the early stages of development (see Fig. 1), it was generally not possible to determine which cell was which. Both $\mathrm{CaP}$ and $\mathrm{VaP}$ were motoneurons based on the criterion that both cells extended axons into the peripheral muscle (Fig. 1, $C, D$ ). Furthermore, because of their large size and the stage at which they extended growth cones, both $\mathrm{CaP}$ and $\mathrm{VaP}$ were considered primary motoneurons as defined by Grunwald et al. (1988). To distinguish these cells, we labeled both cells in the same hemisegment intracellularly with different colored fluorescent dyes at a series of different developmental stages. We found that $\mathrm{CaP}$ and VaP could be distinguished unequivocally by $19-20 \mathrm{~h}$ because by this time the $\mathrm{CaP}$ growth cone had extended along its normal cell-specific 
Figure 1. There may be 1 or 2 distinctive somata in the $\mathrm{CaP} / \mathrm{VaP}$ position. $A$, Nomarski photomicrograph of the right side of segment 12 in a 15.5 $\mathrm{h}$ embryo. This hemisegment has a $\mathrm{CaP}$ motoneuron (arrow), but no VaP. This $\mathrm{CaP}$ has not yet elaborated a growth cone. $B$, Nomarski photomicrograph of the right side of segment 12 in a 15.5 h embryo. This hemisegment has both $\mathrm{CaP}$ and VaP motoneurons (arrows). One of them has just begun to elaborate a growth cone (arrowhead). $C$, Nomarski photomicrograph of the right side of segment 6 in an $18 \mathrm{~h}$ embryo showing a single $\mathrm{CaP}$ motoneuron that has elaborated a growth cone (arrow). VaP is not present in this hemisegment. $D$, Nomarski photomicrograph of the right side of segment 9 in an $18 \mathrm{~h}$ embryo, showing both $\mathrm{CaP}$ and $\mathrm{VaP}$ motoneurons with growth cones (arrows). In this and all subsequent figures, rostral is to the left and dorsal is to the top. sc, spinal cord; $n c$, notochord. Scale bar, $10 \mu \mathrm{m}$.
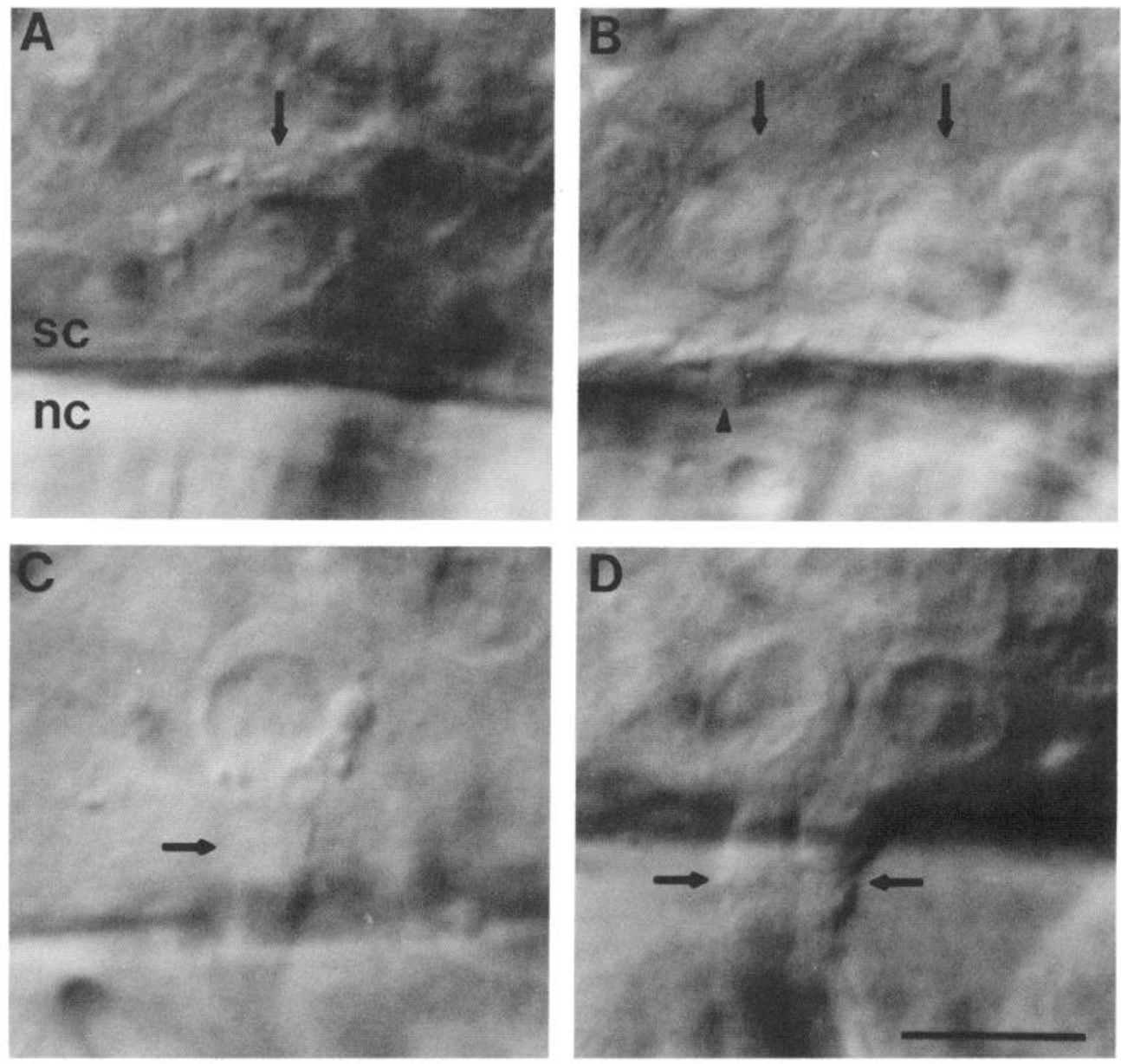

pathway into the ventral muscle, while the VaP growth cone never extended ventrally from the horizontal septum (Fig. 3).

In addition to establishing a criterion by which $\mathrm{CaP}$ and $\mathrm{VaP}$ could be distinguished from one another, our double-labeling studies also revealed that in hemisegments containing VaP, the VaP soma could be either rostral or caudal of the CaP soma. In 33 cases in which $\mathrm{CaP}$ and $\mathrm{VaP}$ were double-labeled between 19 and $24 \mathrm{~h}$, VaP was rostral of CaP in 15 cases and caudal of $\mathrm{CaP}$ in 18 cases.

$\mathrm{VaP}$ and $\mathrm{CaP}$ can be lineally related. In the course of these studies, we labeled 24 VaPs using the lineage tracer method. Seventy-five percent of these VaPs were in hemisegments in which $\mathrm{CaP}$ was also labeled. Although we did not follow the migrations and divisions of the progenitors of the labeled $\mathrm{CaP}$ / $\mathrm{VaP}$ pairs, the pattern we observed is consistent with the idea that the labeled $\mathrm{CaP}$ and VaP within a hemisegment were siblings derived from the final mitosis of a labeled progenitor (see Kimmel and Warga, 1986). Even if these cells were not siblings, they were certainly closely related as they were derived from the same clone. We do not know whether there was a difference between a VaP that was lineally related to the $\mathrm{CaP}$ in the same hemisegment and a $\mathrm{VaP}$ that was unrelated to the $\mathrm{CaP}$ in the same hemisegment.

\section{VaP has a unique identity}

Our finding that the VaP soma could be either rostral or caudal of the $\mathrm{CaP}$ soma suggested that there might be some interaction between these cells that determined which cell became $\mathrm{CaP}$ and which became VaP. For example, the cell whose growth cone left the spinal cord first might always become $\mathrm{CaP}$, forcing the other cell to become VaP. To test this possibility, we ablated the caudal cell of the $\mathrm{CaP} / \mathrm{VaP}$ pair in hemisegments having both $\mathrm{CaP}$ and VaP. Ablations were performed $1-2 \mathrm{hr}$ prior to axogenesis in hemisegments $6-10$ on the right side of $15 \mathrm{~h}$ embryos. We allowed the animals to grow for another $9 \mathrm{hr}$, to $24 \mathrm{~h}$, at which time we determined the identity of the remaining motoneuron in the hemisegment by labeling it intracellularly with Lucifer yellow. If $\mathrm{CaP}$ and VaP interacted in the way predicted by our hypothesis, then we would expect to find only $\mathrm{CaP}$, and never $\mathrm{VaP}$, in hemisegments in which one of the cells had been ablated. However, of 11 hemisegments in which we performed ablations, in 6 cases the remaining cell was $\mathrm{CaP}$ and in 5 cases the remaining cell was VaP. Our interpretation of this result is that $\mathrm{CaP}$ and $\mathrm{VaP}$ have distinct identities by the time their growth cones reach the "choice point" (Eisen et al., 1986) at the horizontal septum. They may have distinct identities prior to axogenesis, although we cannot conclude this from our data.

We also examined whether interactions between $\mathrm{CaP}$ and $\mathrm{VaP}$ influenced cellular identity by performing ablations at earlier developmental stages, when only a single cell was visible in the $\mathrm{CaP} / \mathrm{VaP}$ position. Previous work showed that in hemisegments containing a single motoneuron at this position, that cell was always CaP (Eisen et al., 1986; Myers et al., 1986). Therefore, we would expect that if $\mathrm{CaP}$ and $\mathrm{VaP}$ did not have distinct 

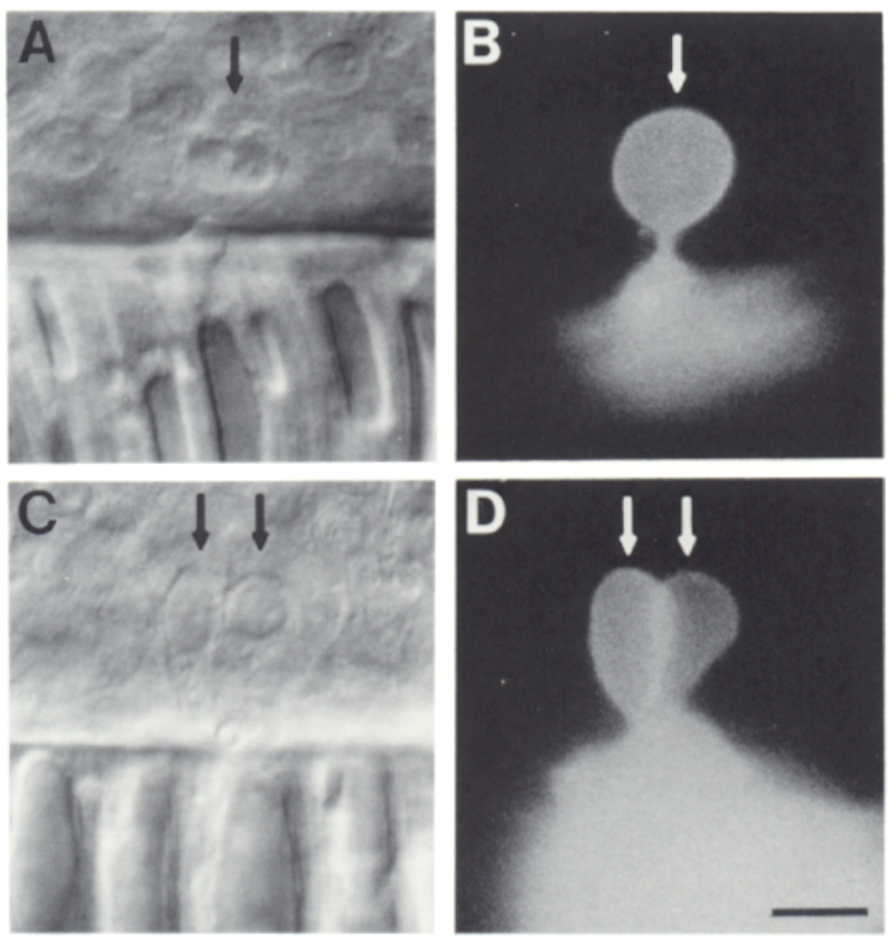

Figure 2. Observations of the presence or absence of VaP using Nomarski optics are accurate. $A$, Nomarski photomicrograph of the right side of segment 9 in a $20 \mathrm{~h}$ embryo showing a CaP motoneuron (arrow) but no VaP. B. Fluorescence photomicrograph of the same segment as that shown in $A$ after retrograde transport of Di-I from a pool applied to the motor nerve at the level of the horizontal septum. Only the $\mathrm{CaP}$ soma (arrow) is labeled. $C$, Nomarski photomicrograph of the right side of segment 8 in a $20 \mathrm{~h}$ embryo showing both CaP and VaP (arrows). $D$. Fluorescence photomicrograph of the same segment as that shown in $C$ after retrograde transport of Di-I from a pool applied to the motor nerve at the level of the horizontal septum. Both the CaP and the VaP somata (arrows) are labeled. Scale bar, $10 \mu \mathrm{m}$.

identities prior to the time of the ablation, the removal of one of these cells might force the remaining cell to become CaP. After the ablation, embryos were allowed to grow for 7-9 hr, and they were then examined to determine whether a primary motoneuron was present in the $\mathrm{CaP} / \mathrm{VaP}$ position and, if so, whether that cell was $\mathrm{CaP}$ or $\mathrm{VaP}$. In half of the cases in which we performed ablations, no cell was observed in the $\mathrm{CaP} / \mathrm{VaP}$ position 7-9 hr after the ablation. This is consistent with our observation that $\mathrm{VaP}$ is not present in all segments (see Figs. 1 and 2), and will be considered further in the following section. In the other half of the cases ( 14 of 28 ), we found that a $\mathrm{CaP}$ or $\mathrm{VaP}$ was present 7-9 hr after the ablation. In 5 of these cases, the cell was $\mathrm{CaP}$ and in 9 cases the cell was VaP. Again, this result is consistent with the idea that $\mathrm{CaP}$ and $\mathrm{VaP}$ already had individual identities by the time of cell-specific pathway selection, and may have already had individual identities prior to axogenesis. These results also provide evidence that the first motoneuron visible in a hemisegment can be either $\mathrm{CaP}$ or $\mathrm{VaP}$.

\section{Distribution of $\mathrm{VaP}$}

$\mathrm{VaP}$ is not present in all hemisegments. As described above, in half (14 of 28) of the hemisegments in which we ablated the first primary motoneuron prior to axogenesis and before a second primary motoneuron was visible, we found no cell in the $\mathrm{CaP} / \mathrm{VaP}$ position $7-9 \mathrm{hr}$ later. This finding corroborated ob-

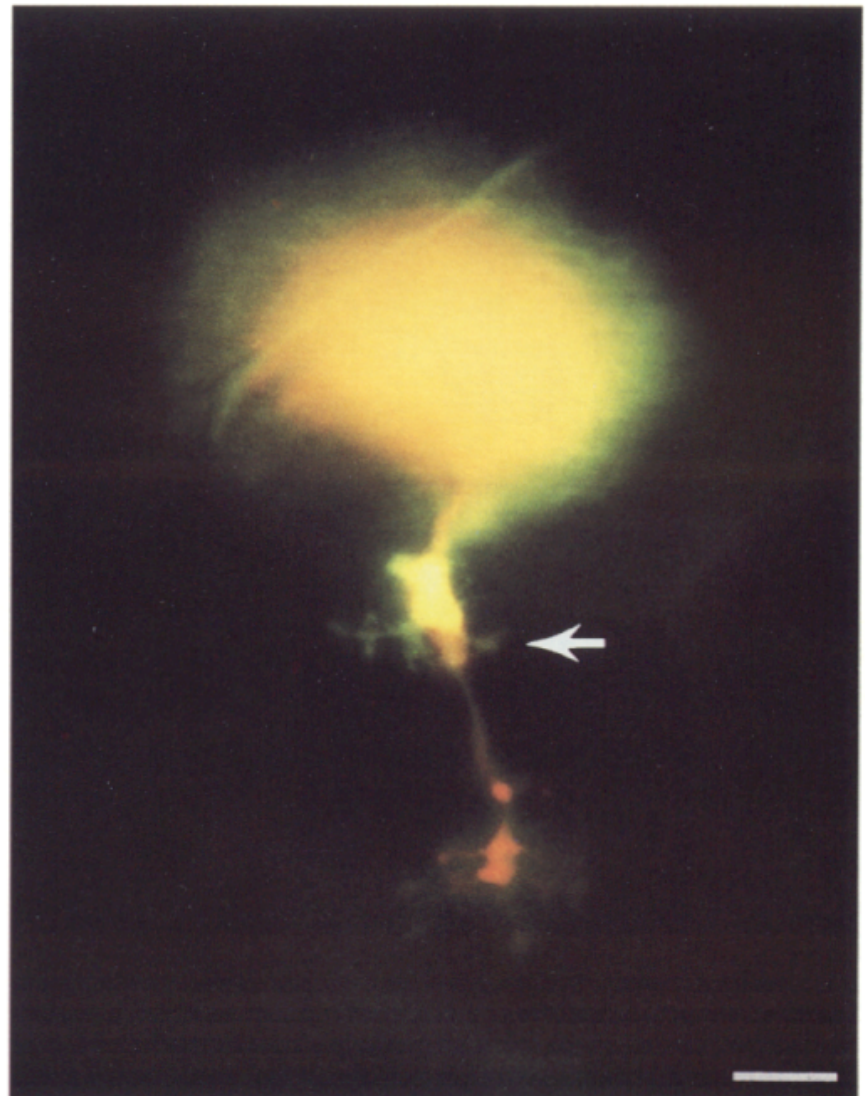

Figure 3. The VaP growth cone does not extend ventral of the horizontal septum. Fluorescence photomicrograph showing a $\mathrm{CaP}$ labeled with sulforhodamine 101 ( $r e d)$ and a VaP labeled with Lucifer yellow (yellow) in segment 9 of a $21 \mathrm{~h}$ embryo. The VaP growth cone has paused at the horizontal septum (arrow), while the CaP growth cone has already extended ventrally. The somata of these cells are out of focus. Scale bar, $10 \mu \mathrm{m}$.

servations using Nomarski optics that $\mathrm{VaP}$ was present in slightly less than half $(47 \%)$ of the trunk hemisegments (Table 1). Not only was $\mathrm{VaP}$ absent from some hemisegments, its distribution was not segment specific (Table 1). Furthermore, the presence of $\mathrm{VaP}$ on one side of a segment did not correlate with its presence on the other side of the same segment (Table 2). Among the embryos we examined, the occurrence of $\mathrm{VaP}$ was highly variable. Some embryos had VaP in as few as $14 \%$ of the hemi-

\begin{tabular}{|c|c|c|c|c|c|c|c|c|}
\hline & \multicolumn{7}{|c|}{ Segment number } & \multirow{2}{*}{$\begin{array}{l}\text { Average } \pm \\
\text { SD }\end{array}$} \\
\hline & 5 & 6 & 7 & 8 & 9 & 10 & 11 & \\
\hline \multicolumn{9}{|l|}{$\mathrm{VaP}$ present } \\
\hline Number & 52 & 53 & 41 & 41 & 46 & 45 & 34 & $44.57 \pm 6.65$ \\
\hline Percent & 55 & 56 & 44 & 44 & 49 & 48 & 36 & $47.43 \pm 6.92$ \\
\hline \multicolumn{9}{|l|}{ VaP absent } \\
\hline Number & 42 & 41 & 53 & 53 & 48 & 49 & 60 & $49.43 \pm 6.65$ \\
\hline Percent & 45 & 44 & 56 & 56 & 51 & 52 & 64 & $52.57 \pm 6.92$ \\
\hline
\end{tabular}

$\mathrm{VaP}$ was present in about half the trunk hemisegments. Both sides of trunk segments 5-11 were examined in 47 18-23 h embryos using Nomarski optics. Although there was a tendency for $\mathrm{VaP}$ to be present more often in rostral segments and less often in caudal segments, this tendency was not statistically significant $(z$ test for population proportion; $p<0.01$ ). 


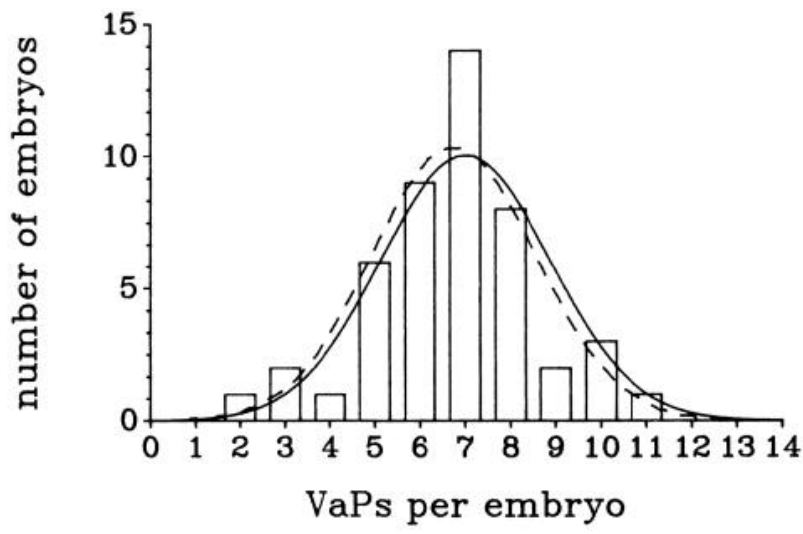

Figure 4. The occurrence of $\mathrm{VaP}$ is highly variable in any given embryo. The presence or absence of $\mathrm{VaP}$ was scored in 14 hemisegments (both sides of segments 5-11) in 47 embryos. This histogram shows the number of embryos in which $\mathrm{VaP}$ was present in a given number of hemisegments, and therefore absent in the remaining hemisegments. For example, there were 9 embryos in which VaP was present in 6 hemisegments and absent in 8 hemisegments. The distribution of $\mathrm{VaP}$ per embryo approximates a normal distribution, shown superimposed on the histogram. The broken line is a normal distribution calculated from the data (mean $\pm \mathrm{SD}=6.74 \pm 1.83$ ), and the solid line is a normal distribution centered around $7.00( \pm 1.87)$. This type of distribution suggests that the presence or absence of $\mathrm{VaP}$ in any given segment during this period of development was a random event.

segments we examined, while other embryos had VaP in as many as $79 \%$ of the hemisegments (Fig. 4).

\section{Fate of VaP}

Each of the 3 primary motoneurons previously described undergoes a stereotyped pattern of development during which it elaborates a characteristic arbor in a cell-specific muscle territory.
Table 2. Asymmetry of VaP distribution

\begin{tabular}{|c|c|c|c|c|c|c|c|c|}
\hline & \multicolumn{7}{|c|}{ Segment number } & \multirow{2}{*}{$\begin{array}{l}\text { Average } \pm \\
\text { SD }\end{array}$} \\
\hline & 5 & 6 & 7 & 8 & 9 & 10 & 11 & \\
\hline \multicolumn{9}{|c|}{ VaP present on both sides } \\
\hline Number & 13 & 16 & 10 & 8 & 12 & 13 & 5 & $11.0 \pm 3.7$ \\
\hline Percent & 28 & 34 & 21 & 17 & 26 & 28 & 11 & $23.4 \pm 7.8$ \\
\hline \multicolumn{9}{|c|}{ VaP present on neither side } \\
\hline Number & 8 & 10 & 16 & 13 & 13 & 11 & 18 & $12.7 \pm 3.5$ \\
\hline Percent & 17 & 21 & 34 & 28 & 28 & 23 & 38 & $27.0 \pm 7.4$ \\
\hline \multicolumn{9}{|c|}{ VaP present on one side only } \\
\hline Number & 26 & 21 & 21 & 26 & 22 & 23 & 24 & $23.3 \pm 2.1$ \\
\hline Percent & 55 & 45 & 45 & 55 & 47 & 49 & 51 & $49.6 \pm 4.5$ \\
\hline
\end{tabular}

VaP was present on both sides of about one-quarter of the trunk segments. To determine whether the distribution of $\mathrm{VaP}$ was bilaterally symmetrical, segments 5-11 were scored for the presence or absence of VaP in 47 18-23 h embryos. For each segment, we determined whether VaP was present or absent on both sides (symmetrical) or was present on one side only (asymmetrical). VaP was symmetrically distributed in about half of the 329 segments examined.

Moreover, each of these cells appears to persist throughout the life of the animal. In contrast, VaP has several possible fates. Most of the VaPs whose development we followed died during embryonic development. Those that survived remained motoneurons and arborized in an exclusive muscle territory. However, there were some cells in the VaP position that appeared to have other fates.

Most VaPs die during embryonic development. Several observations provide evidence that most VaPs died during embryonic development. Using Nomarski optics, we watched 3 unlabeled VaPs die between 20-22 h (Fig. 5A). In each of these 3 cases, when we initially observed the cell, the soma was quite swollen, the nuclear contents appeared granular, and the cytoplasm contained one or more translucent granules of varying
Figure 5. Dying VaPs can be seen with Nomarski optics. A, Nomarski photomicrograph of the right side of segment 9 of a 20 h embryo. A dying VaP (arrowhead) is adjacent to a healthylooking $\mathrm{CaP}$ (arrow). See text for a description of dying cells in this system. $B$, Nomarski photomicrograph of the right side of segment 7 of a $24 \mathrm{~h}$ embryo. A dying $\mathrm{VaP}$ (arrowhead) is barely visible next to a healthy-looking $\mathrm{CaP}$ (arrow). $C$, After the photomicrograph shown in $B$ was taken, the $\mathrm{CaP}$ was impaled with a Lucifer yellow-containing microelectrode and labeled. The fluorescence photomicrograph shows that the healthy cell was indeed a $\mathrm{CaP}$ because its growth cone had extended ventrally from the horizontal septum (arrow). Scale bar, $10 \mu \mathrm{m}$.
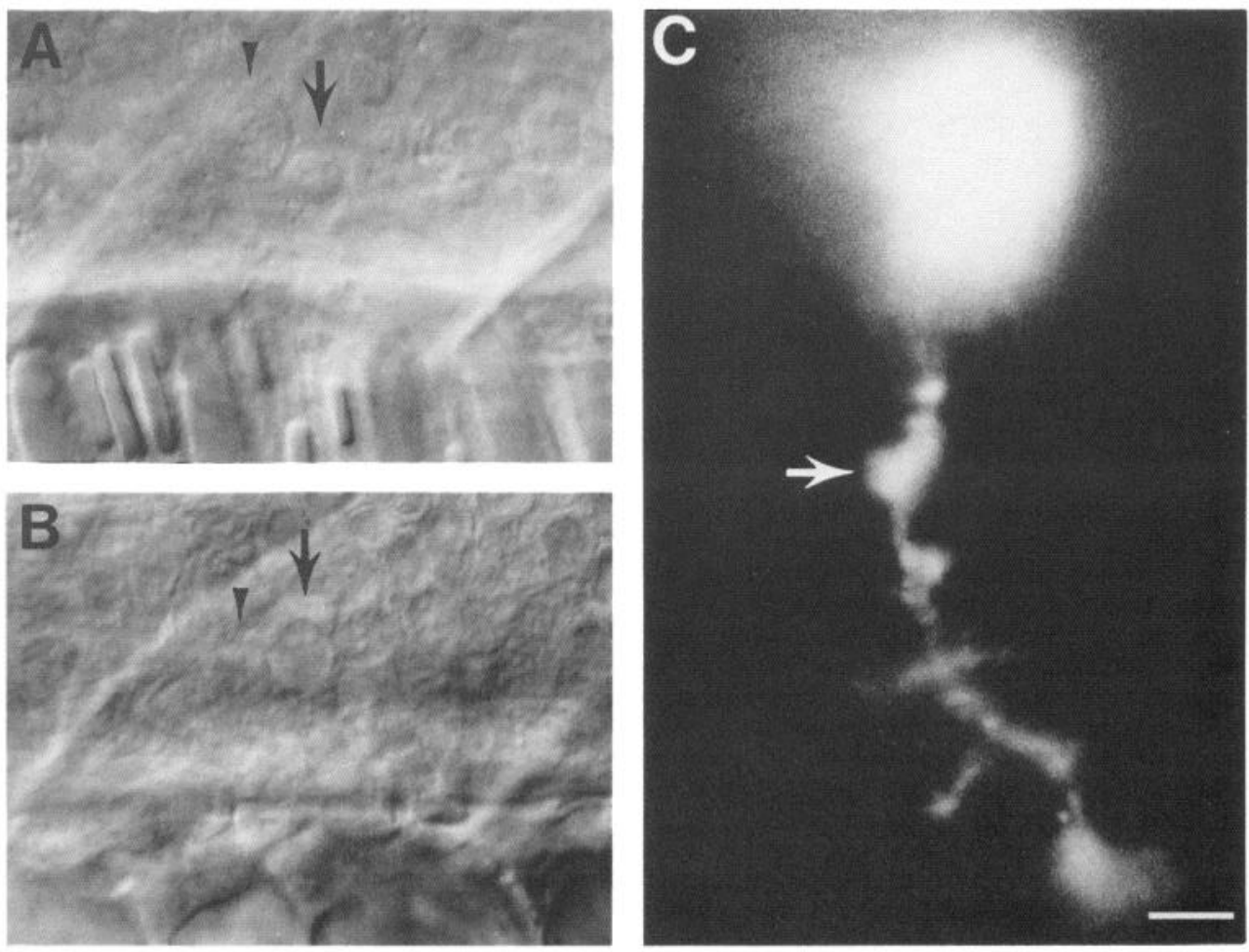


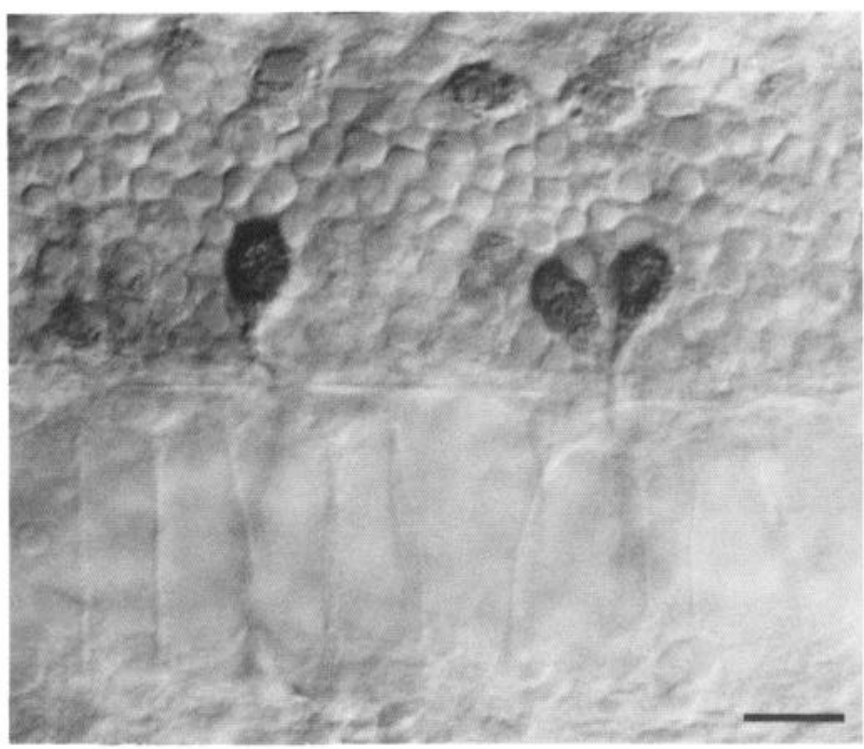

Figure 6. Both $\mathrm{CaP}$ and $\mathrm{VaP}$ show immunoreactivity with the $\mathrm{zn}-1$ monoclonal antibody. This Nomarski photomicrograph shows the right side of segments 14 and 15 in a $24 \mathrm{~h}$ embryo. In segment 14 a single $\mathrm{CaP}$ is present and shows zn-1 immunoreactivity, while in segment 15 both $\mathrm{CaP}$ and $\mathrm{VaP}$ are present and show zn-1 immunoreactivity. Scale bar, $10 \mu \mathrm{m}$.

sizes (approximately $0.5-3.5 \mu \mathrm{m}$ diameter). Within a few minutes, the nucleus appeared to lose its integrity, followed by a loss of integrity of the soma. These observations are reminiscent of the descriptions of cell death termed apoptosis (reviewed in Wyllie et al., 1980). In 6 other cases we observed a dead cell in the position appropriate for $\mathrm{VaP}$, next to a healthy primary motoneuron. In one case, we confirmed that the healthy cell was $\mathrm{CaP}$ by labeling it intracellularly with Lucifer yellow (Fig. $5, B, C)$. We did not observe dead, unlabeled CaPs, MiPs, or RoPs in the more than 300 animals used in these experiments.

To determine whether VaPs died after $24 \mathrm{~h}$, we compared the development of 29 fluorescently labeled VaPs and $28 \mathrm{flu}-$ orescently labeled CaPs. We used labeled cells for these observations because after $24 \mathrm{~h}$ it is difficult to recognize the soma of an individual primary motoneuron unequivocally unless the cell is labeled. However, if a labeled cell dies, we can never be sure that it was not damaged by the photoreactivity of the fluorescent dye. Therefore, we labeled CaPs and VaPs by 2 different methods with 2 different dyes (Di-I and rhodamine dextran) and examined the cells infrequently. To minimize potential photodamage, each of these cells was first observed at $24 \mathrm{~h}$ and was not observed again until $36 \mathrm{~h}$. Most of the labeled VaPs died between 24 and $36 \mathrm{~h}$, while all of the labeled CaPs survived through $36 \mathrm{~h}$. After a labeled cell died, it could no longer be seen using Nomarski optics. However, flecks of fluorescence remained in the region of the soma and along the path of the axon. We do not know whether these flecks were due to dye internalized by other cells or to adherence of dye to cell surfaces or components of the extracellular matrix. Of 12 VaPs labeled with Di-I, only $2(17 \%)$ survived through $36 \mathrm{~h}$. In the same experiment, all $17 \mathrm{Di}-\mathrm{I}$ labeled CaPs survived through $36 \mathrm{~h}$. Motoneurons labeled with rhodamine dextran by the lineagetracer method behaved similarly: 3 of $17(18 \%)$ labeled VaPs survived through $36 \mathrm{~h}$, while in the same experiment all 11 labeled CaPs survived. Thus, $83 \%$ of the labeled VaPs died
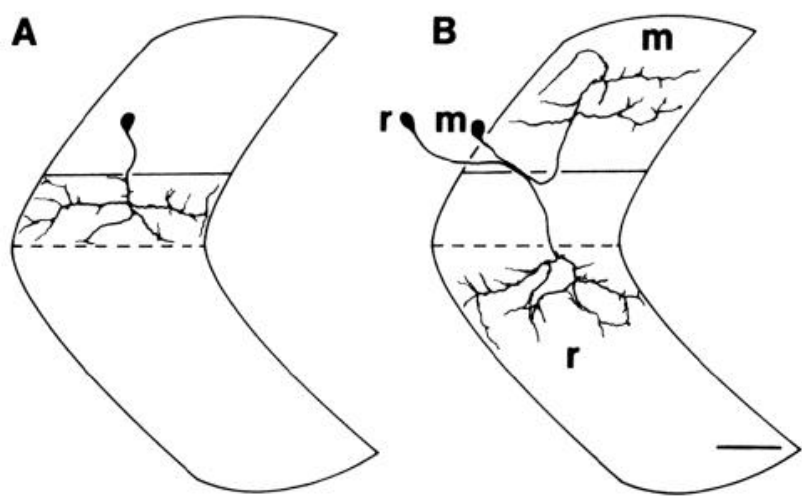

Figure 7. VaP arborizes in a cell-specific muscle territory. A, The VaP shown here was labeled with Di-I and its development followed through $89 \mathrm{~h}$. This VaP arborized in the ventral region of the dorsal muscle of its own hemisegment (8) and did not extend ventral of the horizontal septum (broken line). As with the other primary motoneurons, branches from the axon did not cross segment boundaries. Of the VaPs whose development we followed through this stage, one was on the left side of segment 7 , two were on the right side of segment 8 , and one was on the right side of segment $6 . B$, The arborizations of $\operatorname{MiP}(m)$ and RoP ( $r$ ) in segment 11 of an $87 \mathrm{~h}$ animal complement but do not overlap with the arborization of VaP. The horizontal line denotes the ventral edge of the spinal cord. These cells were drawn from the face of a video monitor. Scale bar, $10 \mu \mathrm{m}$.

between 24-36 h, whereas none of the labeled CaPs died by $36 \mathrm{~h}$.

Some VaPs remain primary motoneurons. The similarity between $\mathrm{VaP}$ and $\mathrm{CaP}$ at early developmental stages suggests that $\mathrm{VaP}$ is of the same class of cells as the other primary motoneurons. Three further observations are consistent with this view. First, like the other primary motoneurons, VaP showed immunoreactivity for the $\mathrm{zn}-1$ monoclonal antibody early in development (Fig. 6). Second, intracellular stimulation of $18 \mathrm{~h}$ VaPs evoked contraction of 2-4 muscle fibers at the horizontal septum in the same hemisegment as the stimulated VaP (data not shown). The contractions followed the stimulus one-forone. Previous work showed that within minutes after the $\mathrm{CaP}$ growth cone was first visible in a segment, a distinctive set of muscle fibers at the horizontal septum of that hemisegment began to contract (Myers et al., 1986). Intracellular stimulation of $18 \mathrm{~h} \mathrm{CaPs}$ also evoked one-for-one contractions of the same muscle fibers (data not shown). We interpret these results to mean that like $\mathrm{CaP}, \mathrm{VaP}$ is a motoneuron and releases transmitter onto muscle fibers in its own hemisegment. Third, in cases where VaP survived, it arborized in an exclusive muscle territory not innervated by other primary motoneurons (Fig. 7). Although the early outgrowth of the $\mathrm{VaP}$ growth cone resembled that of the $\mathrm{CaP}$ growth cone, $\mathrm{VaP}$ did not begin to arborize until after both $\mathrm{CaP}$ and MiP had formed extensive arbors in their cell-specific territories. Both the $\mathrm{CaP}$ and $\mathrm{VaP}$ growth cones reached the horizontal septum between $18-19 \mathrm{~h}$. The $\mathrm{CaP}$ growth cone paused for about an hour (Eisen et al., 1986) and then extended ventrally along its cell-specific pathway. The VaP growth cone paused for much longer, about 6-7 h, and except for a few small branches in the region of the horizontal septum, the VaP axon did not typically form branches before $25 \mathrm{~h}$ (15 of $15 \mathrm{VaPs}$ labeled intracellularly at 24-28 $\mathrm{h}$ with Lucifer yellow). At 25-26 h, some VaPs began branching, and over the next 2-3 d formed extensive arbors in the ventral region of the 
Figure 8. Some cells in the VaP position had both peripheral and central processes. $A$, Combination Nomarski and fluorescence photomicrograph showing a Lucifer yellow-labeled cell in the $\mathrm{VaP}$ position in segment 11 of a 24 h embryo. This cell had a peripheral process that extended almost to the level of the horizontal septum (arrow) and a central process that extended caudally in the spinal cord (arrowhead). B, The same cell photographed using only fluorescence optics. Scale bar, $10 \mu \mathrm{m}$.

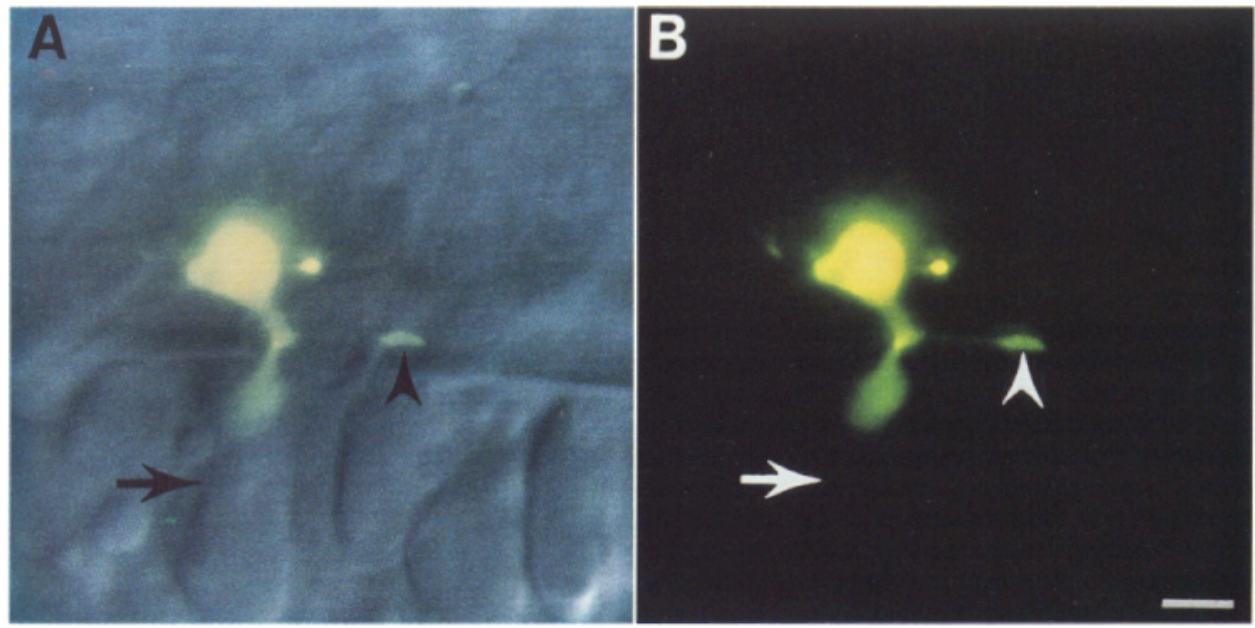

dorsal muscle (Fig. 7A). This region complemented the regions of arborization of MiP and RoP (Fig. 7B). Of the 29 labeled VaPs whose development we followed, 5 survived past $36 \mathrm{~h}$. All 5 of these cells arborized in the same region. Four of these VaPs remained alive for at least $12 \mathrm{~h}$ past the time that embryos typically hatch, at about $72 \mathrm{~h}(3 \mathrm{~d})$. The fifth VaP still appeared healthy at $48 \mathrm{~h}$, when we stopped following its development.

Some neurons in the VaP position may have other fates. A small number $(6 \%)$ of cells that we labeled because we thought they were VaPs or CaPs had an unusual morphology (Fig. 8). The soma of each of these cells was located in the appropriate position to be a $\mathrm{VaP}$ or $\mathrm{CaP}$ and was adjacent to a second soma of similar size and shape. In every case, the labeled cell had a peripheral axon that extended ventrally toward the horizontal septum but did not extend beyond the horizontal septum. In addition to the peripheral axon, each of these cells also had a central process that extended caudally within the spinal cord for a distance of 15-50 $\mu \mathrm{m}$. We did not follow the development of individual cells, because we have not seen cells with this morphology among the cells labeled with lineage-tracer or DiI. Therefore, we do not know the fate of these cells after $25 \mathrm{~h}$. However, the existence of these cells suggests that the ultimate fate of cells in the VaP position may be more complex than simply becoming a primary motoneuron or dying during embryonic development.

The presence of VaP does not affect early pathfinding by other primary motoneurons

To determine whether the presence of $\mathrm{VaP}$ affected pathfinding by the other primary motoneurons, we examined their mor-
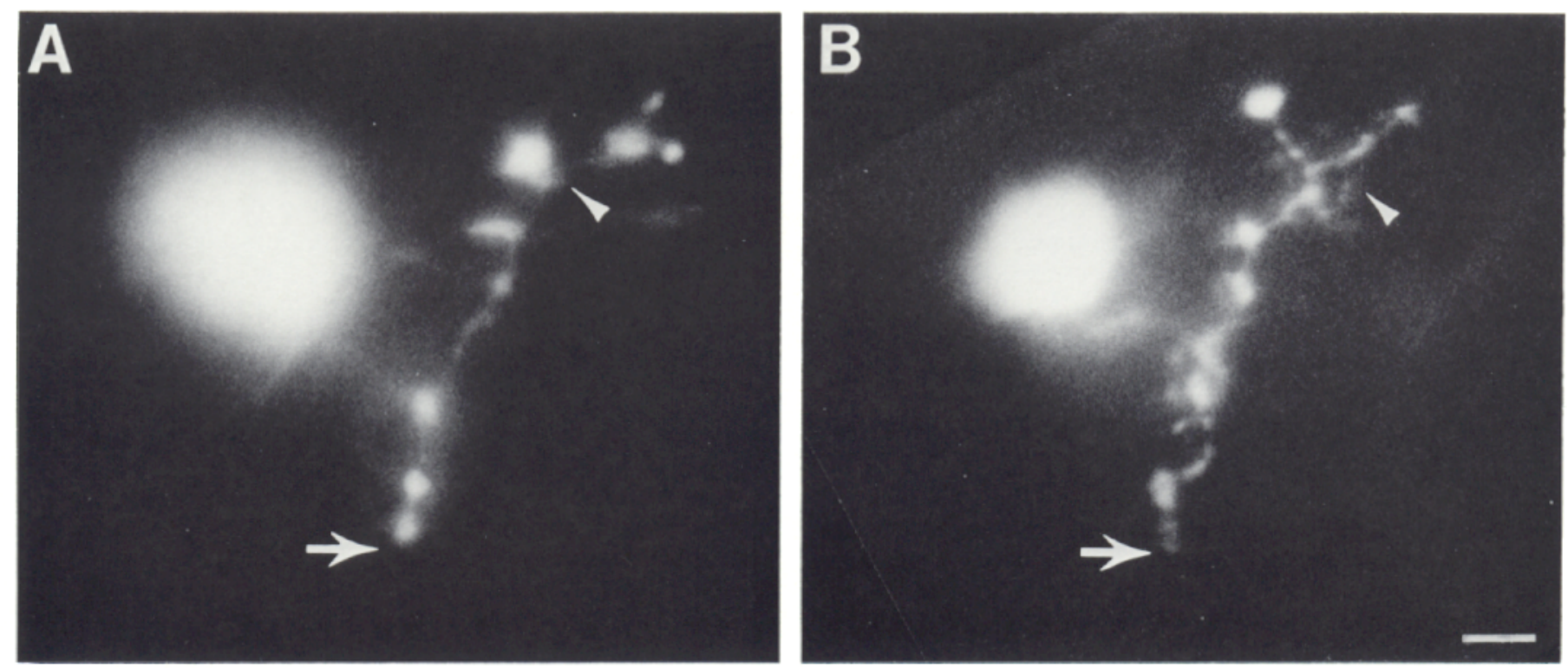

Figure 9. The presence or absence of $\mathrm{VaP}$ does not affect pathfinding by MiP. A, Fluorescence photomicrograph of a Lucifer yellow-labeled MiP in segment 6 of a $24 \mathrm{~h}$ embryo. Both $\mathrm{CaP}$ and $\mathrm{VaP}$ were present in this segment. This MiP had a ventral process that extended to the horizontal septum (arrow) and a dorsal process (arrowhead) that extended along MiP's cell-specific pathway into the dorsal muscle. $B$, Fluorescence photomicrograph of a MiP in segment 8 of a $24 \mathrm{~h}$ embryo. The CaP and $\mathrm{VaP}$ in this segment were ablated prior to axogenesis at $15 \mathrm{~h}$, the embryo allowed to grow for $9 \mathrm{hr}$, and this MiP labeled with Lucifer yellow. The ventral (arrow) and dorsal (arrowhead) processes of this MiP are very similar to those of the MiP shown in the control segment in $A$ and similar to MiPs in segments in which VaP initially was not present (see Eisen et al., 1989). Scale bar, $10 \mu \mathrm{m}$. 
phology in hemisegments containing VaP. Six CaPs, $6 \mathrm{MiPs}$, and $5 \mathrm{RoPs}$ were labeled with Lucifer yellow or sulforhodamine between 22 and $24 \mathrm{~h}$ in hemisegments containing VaP. In each case, the primary motoneurons in hemisegments containing $\mathrm{VaP}$ were indistinguishable from primary motoneurons in hemisegments in which VaP was not present.

Neither the presence nor the absence of $\mathrm{VaP}$ appeared to affect pathfinding by the other primary motoneurons. Previous studies showed that, following ablation of $\mathrm{CaP}$, the MiP growth cone was able to pioneer the peripheral motor pathway and to establish a peripheral arbor that was normal at $24 \mathrm{~h}$ (Eisen et al., 1989). Since the earlier experiments were done in segments in which $\mathrm{VaP}$ was not present, we repeated these experiments in segments containing VaPs. In 8 cases we ablated the rostral cell of the $\mathrm{CaP} / \mathrm{VaP}$ pair prior to axogenesis. In 5 cases the remaining cell was a $\mathrm{VaP}$, and we examined the pathways selected by its growth cone and by the MiP growth cone in the same hemisegment. In every case, the $\mathrm{VaP}$ and $\mathrm{MiP}$ growth cones left the spinal cord at the appropriate position and extended along the normal peripheral pathway to the horizontal septum. In the 4 animals examined at $24 \mathrm{~h}, \mathrm{MiP}$ and $\mathrm{VaP}$ were indistinguishable from MiPs and VaPs in hemisegments containing CaPs.

MiP had a normal morphology in hemisegments in which both $\mathrm{CaP}$ and $\mathrm{VaP}$ were absent. In 12 embryos we ablated both $\mathrm{CaP}$ and VaP prior to axogenesis, and examined the pathway selected by the MiP growth cone. In the absence of both $\mathrm{CaP}$ and $\mathrm{VaP}$, the MiP growth cone left the spinal cord at the appropriate position, pioneered the peripheral motor pathway, and selected its normal cell-specific pathway. Of these 12 embryos, 10 were examined at $24 \mathrm{~h}$, and the MiPs in segments in which $\mathrm{CaP}$ and $\mathrm{VaP}$ had been ablated were found to be indistinguishable from MiPs in segments containing CaPs or containing $\mathrm{CaPs}$ and VaPs (Fig. 9). We conclude that the presence or absence of $\mathrm{VaP}$ did not affect pathfinding by the MiP growth cone because it selected the appropriate pathway in the absence of $\mathrm{CaP}$ (Eisen et al., 1989), in the absence of VaP, and in the absence of both $\mathrm{CaP}$ and VaP.

\section{Discussion}

Initial studies of the innervation of adult zebrafish axial musculture showed that each side of every trunk segment was innervated by 3 individually identifiable primary motoneurons (Westerfield et al., 1986) whose development could be followed from axogenesis (Eisen et al., 1986; Myers et al., 1986) throughout the larval period (Myers, 1985). Why have we only now recognized a fourth primary motoneuron? We offer several possible explanations.

First, in our initial studies (Eisen et al., 1986; Myers et al., 1986), we used the lineage tracer method to follow the development of primary motoneurons. Typically, we restricted our observations to hemisegments in which only a single motoneuron was labeled. Of the $24 \mathrm{VaPs}$ labeled by the lineage tracer method in the present study, $75 \%$ were in hemisegments in which $\mathrm{CaP}$ was also labeled. Thus, labeled VaPs may have been present in our earlier studies in hemisegments that also contained other labeled motoneurons, and therefore were not analyzed.

Second, in previous adult studies (Westerfield et al., 1986), only 3 large motor axons, corresponding to the axons of the $\mathrm{CaP}, \mathrm{MiP}$, and RoP motoneurons, were seen in each of the 8 ventral roots examined. Our present studies provide evidence that initially VaP is only present in about half of the trunk hemisegments, and about $83 \%$ of VaPs die during embryonic development. If no more VaPs died during subsequent developmental stages, less than $10 \%$ of the adult trunk hemisegments would contain a VaP. Therefore, a sample of ventral roots from only 8 hemisegments is unlikely to have included any hemisegments containing a VaP.

\section{Similarities and differences between VaP and the other primary motoneurons}

Previous studies showed that $\mathrm{CaP}, \mathrm{MiP}$, and RoP are remarkably stereotyped in their development (Eisen et al., 1986; Myers et al., 1986). In hemisegments in which it was present, $\mathrm{VaP}$ was similar to the other 3 primary motoneurons in a number of important features: (1) The VaP soma was so similar in size and shape to the CaP soma that these cells were not distinguishable until 2-3 hr after axogenesis, (2) VaP underwent axogencsis at about the same time as the $\mathrm{CaP}$ in the same hemisegment, (3) $\mathrm{VaP}$ showed immunoreactivity with the $\mathrm{zn}-1$ monoclonal antibody at the same time as the other primary motoneurons, (4) stimulation of VaP evoked contraction of muscle fibers in the appropriate hemisegment, and (5) in hemisegments in which it survived, VaP arborized in an exclusive territory not innervated by other primary motoneurons.

As stereotypy seems to be the hallmark of the previously described primary motoneurons, variability seems to be the hallmark of VaP. The distribution and other features of $\mathrm{VaP}$ deviated from the stereotyped pattern characteristic of the other primary motoneurons in several important ways: (1) VaP was not present in every trunk hemisegment, (2) the VaP soma did not have a stereotyped spinal cord position relative to the other primary motoneurons, (3) VaP could extend its growth cone before, after, or simultaneously with $\mathrm{CaP}$, and (4) $\mathrm{VaP}$ had several different possible fates. Each of these features is discussed below.

Variable distribution. Using 3 independent methods-observations with Nomarski optics, retrograde labeling with Di-I, and immunolabeling with the $\mathrm{zn}-1$ monoclonal antibody - we found that from 18-24 $\mathrm{h} \mathrm{VaP}$ was present in less than half of the trunk hemisegments examined. This is in marked contrast to $\mathrm{CaP}, \mathrm{MiP}$, and RoP, each of which is present in every trunk segment. Furthermore, the distribution of VaP suggested that its presence or absence in any given hemisegment was independent of its presence or absence in any other hemisegment. We do not know what regulates the presence of $\mathrm{VaP}$ in a hemisegment. One possibility is that initially $\mathrm{VaP}$ is present in all trunk hemisegments and that individual VaPs die at various times during development. Thus, our observation that $\mathrm{VaP}$ is present in less than half of the trunk hemisegments might result from death of about half of the VaPs by the time we can visualize the cell with Nomarski optics. Another possibility is that VaP is cryptically present in segments in which it is not obvious by Nomarski observation. Retrograde labeling with Di-I suggests that this is not likely. However, we have not ruled out the possibility that the somata of some VaPs may not grow as much as the somata of the other primary motoneurons during development (see Westerfield et al., 1986); thus, at later developmental times some VaPs might become cryptic because they would resemble smaller secondary motoneurons.

Variable soma position and variable time of axonal outgrowth. The VaP soma had a variable position in the spinal cord, either rostral or caudal to the $\mathrm{CaP}$ soma, placing it between $\mathrm{CaP}$ and MiP of its own hemisegment, or between CaP of its own hemi- 
segment and RoP of the next caudal hemisegment. Of course, in hemisegments containing $\mathrm{VaP}$, the $\mathrm{CaP}$ soma position was also variable. Because of this variability in soma position, and the fact that either $\mathrm{VaP}$ or $\mathrm{CaP}$ could be the first primary motoneuron to extend a growth cone into the periphery, VaP and $\mathrm{CaP}$ could not be distinguished from one another prior to the time that CaP selected its cell-specific pathway. Despite this variability, following ablation of $\mathrm{CaP}, \mathrm{VaP}$ did not extend its growth conc along the vacant CaP pathway by $24 \mathrm{~h}$, although we have not ruled out the possibility that it might do so at a later time. Thus, our ablation experiments provide evidence that $\mathrm{CaP}$ and $\mathrm{VaP}$ had unique identities by the time of cellspecific pathway selection, and they strongly suggest that $\mathrm{CaP}$ and $\mathrm{VaP}$ had unique identities prior to axogenesis. This is reminiscent of observations from the grasshopper (Raper et al., 1983), in which the sibling $G$ and $C$ neurons could not be distinguished from one another prior to axonal pathway selection because of the variability in soma position. We are currently exploring the possibility that the position of the VaP soma influences the subsequent fate of the cell.

Variable fate. Unlike the other primary motoneurons, VaP appeared to have at least 2 possible fates, life as a primary motoneuron or death. In addition, it is possible that VaP might have other fates, as neurons in the VaP position occasionally had central processes in addition to the peripheral process characteristic of primary motoneurons.

In some hemisegments, VaP was a primary motoneuron that survived at least through the beginning of the larval period of development. We observed $4 \mathrm{VaPs}$, labeled by 2 different methods and located in 3 different hemisegments, through the first day of larval development. In each case, VaP arborized in an exclusive muscle territory that was not innervated by other primary motoneurons.

In some hemisegments, VaP died during embryonic development. Even though most of the VaPs that we observed to die were labeled, we have several reasons for believing that these observations accurately reflect the natural occurrence of $\mathrm{VaP}$ death, and not simply damage, although they may not accurately reflect the frequency of VaP death. First, we have observed the death of unlabeled VaPs, but not unlabeled CaPs, MiPs, or RoPs. The specificity of this phenomenon suggests that it was not some sort of artifact caused by our observations. Second, we observed death of labeled VaPs in experiments in which all the labeled CaPs survived, although we cannot rule out the possibility that VaP was simply more sensitive to photodamage than the other primary motoneurons. VaPs that survived through $36 \mathrm{~h}$ may survive indefinitely. In grasshoppers, identified neurons may die in some segments and not in others, or thcy may live indefinitely if they survive through a particular period of embryonic development (Bate et al., 1981). Third, in our earlier studies there was one case in which there were 4 labeled cells that all looked like primary motoneurons in a single hemisegment. One of these cells died sometime between 24-48 h (J. S. Eisen and P. Z. Myers, unpublished observations). This finding is consistent with the results from our current studies showing that labeled VaPs typically died in embryos in which labeled CaPs survived.

In some hemisegments, a neuron with a soma of the appropriate size and shape to be $\mathrm{VaP}$, and located in the position appropriate for $\mathrm{VaP}$, extended a central process caudally in the spinal cord, in addition to its peripheral process in the muscle. We do not yet know the ultimate fate of these cells. The central process may simply be a "mistake" made by a small percentage of developing VaPs. However, the presence of this cell suggests that the fate of VaPs may be more complex than simply the choice between being a primary motoneuron and dying.

\section{Death of an identified motoneuron}

Cell death is a widespread phenomenon during development (Purves and Lichtman, 1985). In other vertebrates, approximately half of the lateral motor column motoneurons die during development. The major period of motoneuron death occurs after motoneurons have extended growth cones to their targets (Chu-Wang and Oppenheim, 1978), and probably after the establishment of at least some functional connections (Pittman and Oppenheim, 1979). In general, innervation specificity is not altered by motoneuronal death, suggesting that death is not an error-correction mechanism (Lance-Jones and Landmesser, 1980, 1981; Betz, 1987). Because some motoneurons can be rescued by adding additional target area experimentally (Hollyday and Hamburger, 1976), and most can be rescued by suppression of muscular activity with nicotinic antagonists (Pittman and Oppenheim, 1979; Ding et al., 1983), it is thought that motoneuron survival is mediated by competition for some sort of muscle-derived trophic factor whose production is regulated by activity (Pittman and Oppenheim, 1979; Betz, 1987).

How does the death of $\mathrm{VaP}$ in some hemisegments fit into the prevailing picture of vertebrate motoneuron death? Most of the labeled VaPs died sometime between 24-36 h. We also observed the death of a few unlabeled VaPs between $20-23 \mathrm{~h}$. All VaPs have extended a peripheral process to the level of the horizontal septum by $20 \mathrm{~h}$, and most VaPs have not begun to elaborate branches in their cell-specific territory until after 25 h. Thus, like other vertebrate motoneurons, these cells died after the initial phase of axonal elongation. However, at least some of them died before extending into their ultimate target region. This observation, in combination with studies suggesting that zebrafish primary motoneurons do not compete for muscle territory (Eisen et al., 1989; D. Liu and M. Westerfield, unpublished observations), suggests that competition for a musclederived trophic substance is unlikely to be the only factor in the demise of VaPs. However, we cannot rule out the possibility that interactions between VaP and the other primary motoneurons may influence the chances of $\mathrm{VaP}$ survival.

The death of $\mathrm{VaP}$ resembles the death of individually identified invertebrate cells more than it resembles the death of populations of vertebrate motoneurons. In some invertebrates, individually identified cells are programmed to die at specific developmental stages (Sulston and Horvitz, 1977; Horvitz et al., 1982; Hedgecock et al., 1983; Ellis and Horvitz, 1986), and in other cases they die as a result of specific environmental interactions (Sulston et al., 1978; Truman and Schwartz, 1982; Martindale and Shankland, 1988). Because some VaPs do survive throughout embryonic development, we speculate that some environmental signal, rather than a developmental "preprogram," may cause VaP to die. Such a signal would have to be autonomous for each hemisegment, since VaP survival appears to be an autonomous event in each hemisegment. One possibility is that interactions between $\mathrm{VaP}$ and the other primary motoneurons might determine whether VaP survives or dies. For example, VaP survival might be regulated by a signal that depended on the position of the VaP soma relative to the somata of the other primary motoneuron. Another possibility is that afferent neurons may provide important signals for influencing 
whether VaP survives, and perhaps its ultimate morphology and connectivity.

\section{VaP does not affect early pathfinding by the other primary motoneurons}

We found that the growth cones of the other primary motoneurons selected the appropriate pathways whether $\mathrm{VaP}$ was present or absent. Our previous studies (Eisen et al., 1989) showed that ablation of $\mathrm{CaP}$ did not affect the ability of the MiP growth cone to select its appropriate cell-specific pathway. Moreover, by $24 \mathrm{~h} \mathrm{MiP}$ had established a normal peripheral arbor in the appropriate region of muscle. All of our original results were obtained in segments in which $\mathrm{VaP}$ was not present. Because the presence of $\mathrm{VaP}$ is variable, we would not expect that ablation of $\mathrm{VaP}$ would affect pathfinding by $\mathrm{MiP}$ in any way. Our present results provide evidence that this is the case; MiP selects its normal pathway whether $\mathrm{VaP}$ is naturally absent in a segment, or has been artificially removed by ablation. We have also extended these findings to show that the absence of both $\mathrm{CaP}$ and $\mathrm{VaP}$ does not affect pathfinding by the MiP growth cone.

Does the presence of $\mathrm{VaP}$ affect later motoneuronal development? Although the presence of $\mathrm{VaP}$ does not affect pathfinding by the other primary motoneurons, the fact that in some hemisegments VaP innervates an exclusive muscle territory raises the question of the pattern of innervation of this territory in hemisegments in which $\mathrm{VaP}$ initially is not present or dies during embryonic development. It is possible that in most hemisegments this region of muscle does not receive innervation from a primary motoneuron, but this seems unlikely. An alternative possibility is that either MiP or RoP or both MiP and RoP innervate this territory in hemisegments in which $\mathrm{VaP}$ is not present. This hypothesis predicts that we should find MiPs and/ or RoPs with somewhat different innervation territories depending on whether $\mathrm{VaP}$ is present or absent. Furthermore, this hypothesis suggests that the primary motoneurons might compete for muscle fibers in specific regions of a hemisegment, although they do not compete for cell-specific pathways (Pike and Eisen, 1990). This prediction could be tested by ablating $\mathrm{VaP}$ and determining whether the arborization of MiP or RoP expands to fill in the vacant territory.

\section{References}

Bate, M., C. S. Goodman, and N. C. Spitzer (1981) Embryonic development of identified neurons: Segment-specific differences in the H cell homologues. J. Neurosci. 1: 103-106.

Betz, W. J. (1987) Motoneuron death and synapse elimination in vertebrates. In The Vertebrate Neuromuscular Junction, M. M. Salpeter, ed., pp. 117-162, Liss, New York.

Blight, A. R. (1978) Golgi-staining of "primary" and "secondary" motoneurons in the developing spinal cord of an amphibian. J. Comp. Neurol. 180: 679-690.

Chu-Wang, I. W., and R. W. Oppenheim (1978) Cell death of motoneurons in the chick embryo spinal cord. II. A quantitative and qualitative analysis of degeneration in the ventral roots, including evidence for axon outgrowth and limb innervation prior to cell death. J. Comp. Neurol. 177: 59-86.

Ding, R., J. K. S. Jansen, N. G. Laing, and H. Tonnesen (1983) The innervation of skeletal muscle in chickens curarized during early development. J. Neurocytol. 12: 887-919.

Eisen, J. S., P. Z. Myers, and M. Westerfield (1986) Pathway selection by growth cones of identified motoneurons in live zebrafish embryos. Nature 320: 269-271.

Eisen, J. S., S. H. Pike, and B. Debu (1989) The growth cones of identified motoneurons in embryonic zebrafish select appropriate pathways in the absence of specific cellular interactions. Neuron 2 1097-1 104 .

Ellis, H. M., and H. R. Horvitz (1986) Genetic control of programmed cell death in the nematode $C$. elegans. Cell 44: 817-829.

Grunwald, D. J., C. B. Kimmel, M. Westerfield, C. Walker, and G. Streisinger (1988) A neural degeneration mutation that spares primary neurons in the zebrafish. Dev. Biol. 126: 115-128.

Hanneman, E., W. K. Metcalfe, W. W. Trevarrow, C. B. Kimmel, and M. Westerfield (1988) Segmental pattern of development of the hindbrain and spinal cord of the zebrafish embryo. Development 103 . 49-58.

Hedgecock, E. M., J. E. Sulston, and J. N. Thomson (1983) Mutations affecting programmed cell deaths in the nematode Caenorhabditis elegans. Science 220: 1277-1279.

Hollyday, M., and V. Hamburger (1976) Reduction of the naturally occurring motor neuron loss by enlargement of the periphery. J. Comp. Neurol. 170: 311-320.

Honig, M. G., and R. I. Hume (1986) Fluorescent carbocyanine dyes allow living neurons of identified origin to be studied in long-term culture. J. Cell Biol. 103: 171-187.

Horvitz, H. R., H. M. Ellis, and P. W. Sternberg (1982) Programmed cell death in nematode development. Neurosci. Comment. 1: 56-65.

Kimmel, C. B., and R. M. Warga (1986) Tissue-specific lineages originate in the gastrula of the zebrafish. Science 231: 365-368.

Kimmel, C. B., and R. M. Warga (1987) Indeterminate cell lineage of the zebrafish embryo. Dev. Biol. 124: 269-280.

Kuwada, J. Y. (1986) Cell recognition by neuronal growth cones in a simple vertebrate embryo. Science $233: 740-746$.

Lance-Jones, C., and L. Landmesser (1980) Motoneuron projection patterns in chick hind limb following partial reversals of the spinal cord. J. Physiol. (Lond.) 302: 581-602.

Lance-Jones, C., and L. Landmesser (1981) Pathway selection by embryonic chick motoneurons in an experimentally altered environment. Proc. R. Soc. London [Biol.] 214: 19-52.

Martindale, M. Q., and M. Shankland (1988) Developmental origin of segmental differences in the leech ectoderm: Survival and differentiation of the distal tubule cell is determined by the host segment. Dev. Biol. 125: 290-300.

Metcalfe, W. K., B. Mendelson, and C. B. Kimmel (1986) Segmental homologies among reticulospinal neurons in the hindbrain of the zebrafish larva. J. Comp. Neurol. 251: 147-159.

Myers, P. Z. (1985) Spinal motoneurons of the larval zebrafish. J. Comp. Neurol. 236: 555-561.

Myers, P. Z., J. S. Eisen, and M. Westerfield (1986) Development and axonal outgrowth of identified motoneurons in the zebrafish. J. Neurosci. 6: 2278-2289.

Pike, S. H., and J. S. Eisen (1990) Identified primary motoneurons in embryonic zebrafish select appropriate pathways in the absence of other primary motoneurons. J. Neurosci. 10: 44-49.

Pittman, R., and R. W. Oppenheim (1979) Cell death of motoneurons in the chick embryo spinal cord. IV. Evidence that a functional neuromuscular interaction is involved in the regulation of naturally occurring cell death and the stabilization of synapses. J. Comp. Neurol. 187: 425-446.

Purves, D., and J. W. Lichtman (1985) Principles of Neural Development, Sinauer Assoc., Sunderland, MA.

Raper, J. A., M. Bastiani, and C. S. Goodman (1983) Pathfinding by neuronal growth cones in grasshopper embryos. II. Selective fasciculation onto specific axonal pathways. J. Neurosci. 3: $31-41$.

Sulston, J. E., and H. R. Horvitz (1977) Postembryonic cell lineages of the nematode Caenorhabditis elegans. Dev. Biol. 56: 110-156.

Sulston, J. E., D. G. Albertson, and J. N. Thomson (1978) The Caenorhabditis elegans male: Postembryonic development of nongonadal structures. Dev. Biol. 78: 542-576.

Truman, J. W. (1984) Cell death in invertebrate nervous systems. Annu. Rev. Neurosci. 7: 171-188.

Truman, J. W., and L. M. Schwartz (1982) Programmed death in the nervous system of a moth. TINS 5: 270-273.

Westerfield, M., J. McMurray, and J. S. Eisen (1986) Identified motoneurons and their innervation of axial muscles in the zebrafish. J. Neurosci. 6: 2267-2277.

Wyllie, A. H., J. F. R. Kerr, and A. R. Currie (1980) Cell death: The significance of apoptosis. Int. Rev. Cytol. 68: 251-306. 